\title{
An Epidemic of Hepatitis A - Liaoning Province, 2020
}

\author{
Jing Sun ${ }^{1,8}$; Yuanqiu Li ${ }^{2,8}$; Xing Fang, ${ }^{3,8}$; Yan Wang; ; Yinan $\mathrm{Han}^{4}$; Yang $\mathrm{Liu}^{5}$; Jingyuan $\mathrm{Cao}^{6}$; \\ Wenting Zhou ${ }^{6}$; Hui Zheng, ${ }^{2, *}$; Wenqing Yao ${ }^{1, *}$
}

\section{Summary}

What is already known about this topic?

Hepatitis A (HA) is caused by acute hepatitis A virus (HAV) infection and was once very common in China. Following the 2008 introduction of the HA vaccine into the national Expanded Program on Immunization (EPI), the incidence of reported HA in China decreased markedly. However, HA epidemics still occur in Liaoning Province every 3-5 years, although with far fewer cases than in the pre-HA-vaccination era.

\section{What is added by this report?}

Between January 1, 2020 and March 18, 2020, the number of reported cases of HA in Dalian and Dandong cities of Liaoning Province increased significantly compared with the same period in previous years. All cases were sporadic, and cases were seen in nearly every township. The increase in HA occurred one month after local fresh seafood became available with most cases being among adults. A casecontrol study showed that consuming raw or undercooked seafood, clams, snapping shrimp, and oysters were significantly associated with the increase in HA.

What are the implications for public health practices?

Strengthening health education for residents to avoid consumption of raw seafood and encouraging HAV vaccination of adults aged 20 to 54 years are important to prevent periodic HAV endemic outbreaks. Further multisectoral cooperation must be emphasized on HA surveillance in areas with a high prevalence of HA.

\section{BACKGROUND}

In February 2020 compared with February 2019, there was a $138.2 \%$ increase of cases of hepatitis A (HA) reported to the National Notifiable Disease Report System (NNDRS) from Liaoning Province, and $77.6 \%$ of the cases in Liaoning were from two coastal cities - Dalian and Dandong. All cases were sporadic, and cases were seen in nearly every township of the two cities. Through an interview survey of HA cases and a case-control study, we found that consuming raw or undercooked seafood was significantly associated with the increase in HA. Local governments have taken a series of measures including health education and restriction of the sale of seafood products in markets. During March 11-16, the China CDC, Liaoning Provincial CDC, and Dalian and Dandong CDCs conducted a joint investigation and identified the consumption of raw seafood as the main risk factors associated with the HA increase. We report results of the investigation and recommendations to prevent similar epidemics.

\section{INVESTIGATION AND RESULTS}

All cases of hepatitis A were laboratory confirmed according to the Diagnostic Criteria of Viral Hepatitis A (WS 298-2008) (1). Based on date of onset, 3,511 HA cases were reported nationwide through NNDRS between January 1, 2020 and March 18, 2020, which was a decrease of $12.3 \%$ compared with the 4,003 cases reported across the nation during the same period last year. In contrast, HA cases reported from Liaoning Province in January 1 through March 18 increased from 700 in 2019 to 1,361 in 2020, accounting for approximately one-third of all cases reported nationwide. After integration of the HA vaccine into the national Expanded Program on Immunization (EPI) in 2008, HA had occurred at relatively low levels in Liaoning with periodic increases in every 3-5 years, and the most recent increase was in 2014-2016. In 2020 , the number of reported HA cases increased markedly in the first 2 months of the year but began to decrease on March 4 (Figures 1 and 2).

There were 426 and 586 cases reported from two coastal cities, Dalian and Dandong, which accounted for $74.36 \%(1,012 / 1,361)$ of all cases reported from Liaoning. Zhuanghe County of Dalian and Donggang County of Dandong reported 262 (62.50\%, 262/426) and $290(49.49 \%, 290 / 586)$ cases, which was more 




FIGURE 1. Weekly reported hepatitis A (HA) cases in Liaoning Province, 2004 through Week 11 of 2020.

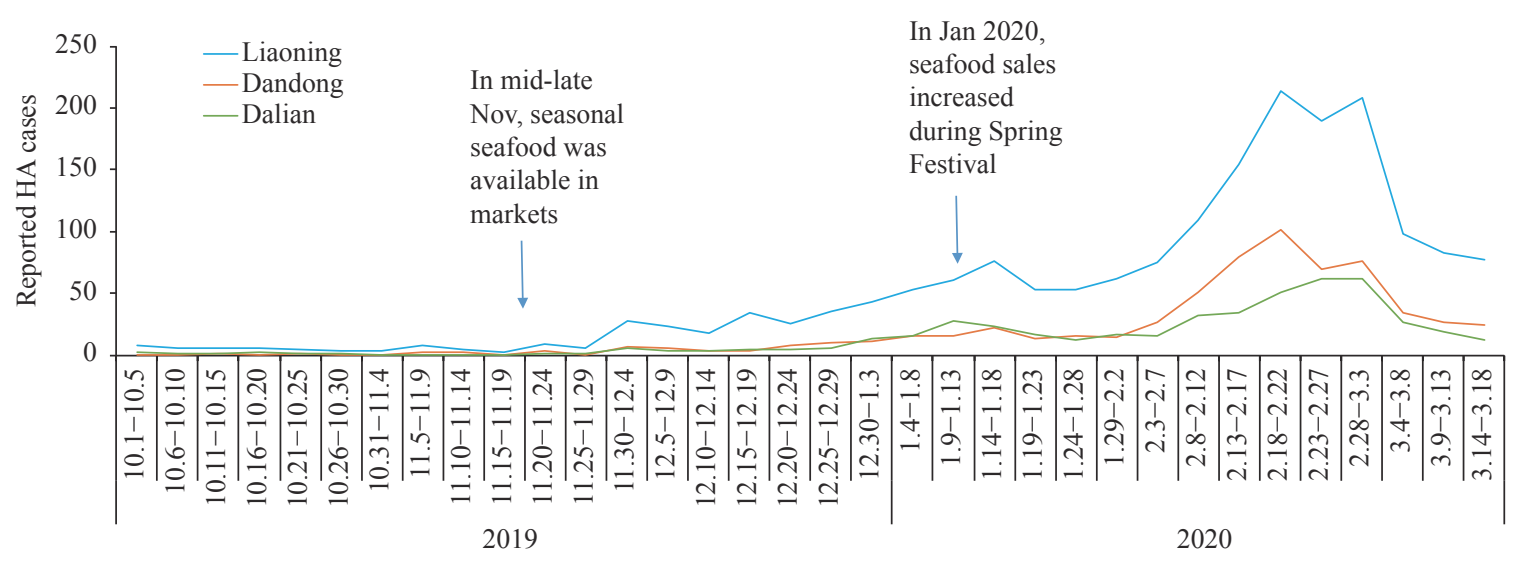

FIGURE 2. Seafood sales timeline and daily distribution of reported hepatitis A (HA) cases in Liaoning, October 1, 2019 to March 18, 2020.

than any other county (Figure 3).

Most cases were among adults that were aged 30-54 years in Dalian and aged 30-49 years in Dandong, which represented $85.4 \%(364 / 426)$ and $82.6 \%$ $(484 / 586)$ of the cases in the two cities. There were 4 $(0.39 \%, 4 / 1,012)$ reported cases among children less than 15 years of age, and 3 of the 4 children had no history of HAV vaccination. By occupation, $50.9 \%$ $(515 / 1,012)$ of HA cases were among farmers and $31.2 \%(316 / 1,012)$ were among household workers or unemployed individuals.

Local CDCs conducted routine epidemiological investigations of all reported and confirmed HA cases in face-to-face or telephone interviews $(n=191)$. The interviews focused on five themes including eating habits, drinking water, types of seafood eaten, diningout behavior, and sources of food during their incubation period. We analyzed data from case interviews conducted between January and early March in Zhuanghe County and found that $71.2 \%$ $(104 / 146), 36.9 \%(31 / 84)$, and $13.3 \%(2 / 15)$ of interview subjects who consumed oysters, snapping shrimp, or cockles ate them raw. During the same time in Dandong, the percent of HA cases with a history of seafood consumption in 2020 was $84.7 \%$ (287/339), which was higher than in 2018 (72.0\%) and 2019 (61.0\%) (local, unpublished data).

We compared sales of local seafood during the two months prior to the HA increase with sales during the HA epidemic. We found that HA case reports began to increase in December 2019, approximately one month after local seafood became available in November. Following a sharp increase of seafood sales during Spring Festival in January 2020, there was a peak of HA cases in February and early March (Figure 2).

The case-control study was conducted by Dalian CDC using face-to-face and telephone interviews. All 191 confirmed HA cases reported between January 1, 2020 and March 7, 2020 in Zhuanghe County were enrolled as the case group, and 277 healthy individuals residing in the same county were recruited for the control group. Controls were healthy adults living in the same town as a case, with no history of HA, and who had not received HAV vaccine. The questionnaire was designed, tested, and revised by Dalian CDC; all data, including eating habits, types of drinking water, 


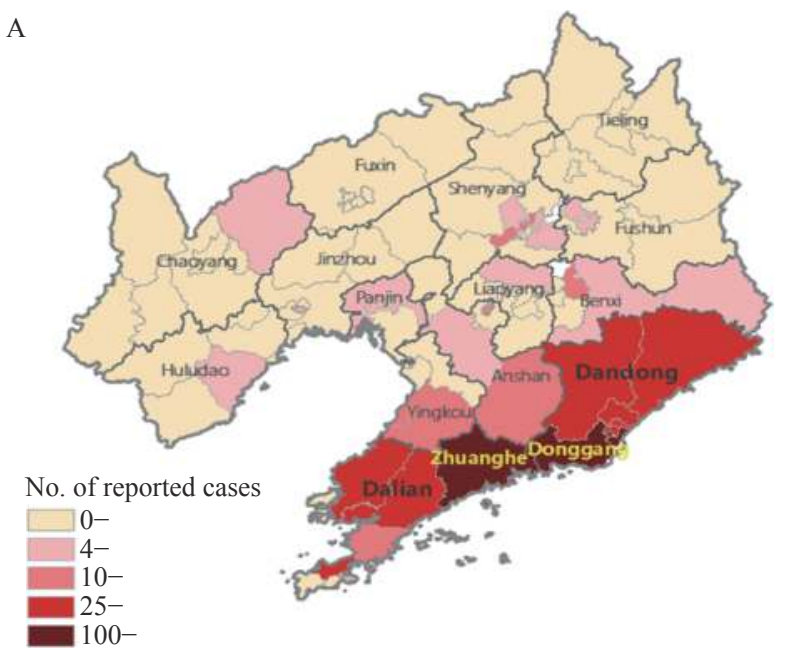

1 Dot $=1$ case

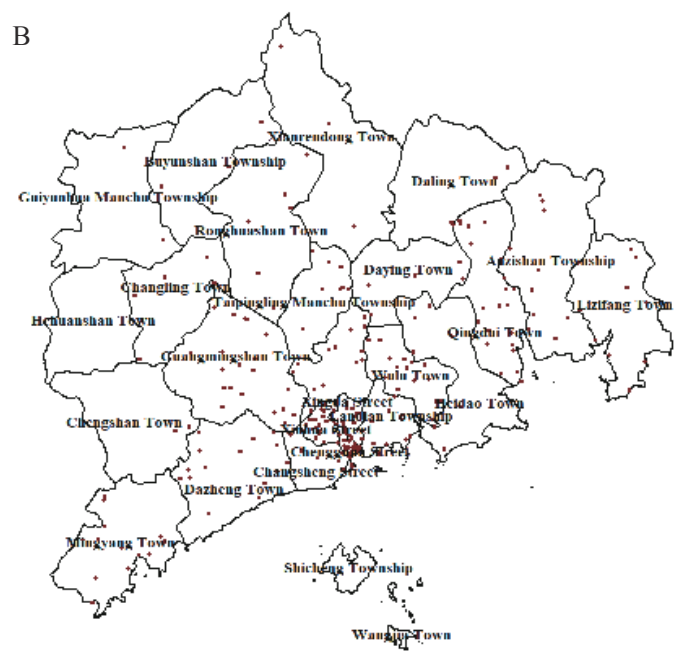

C

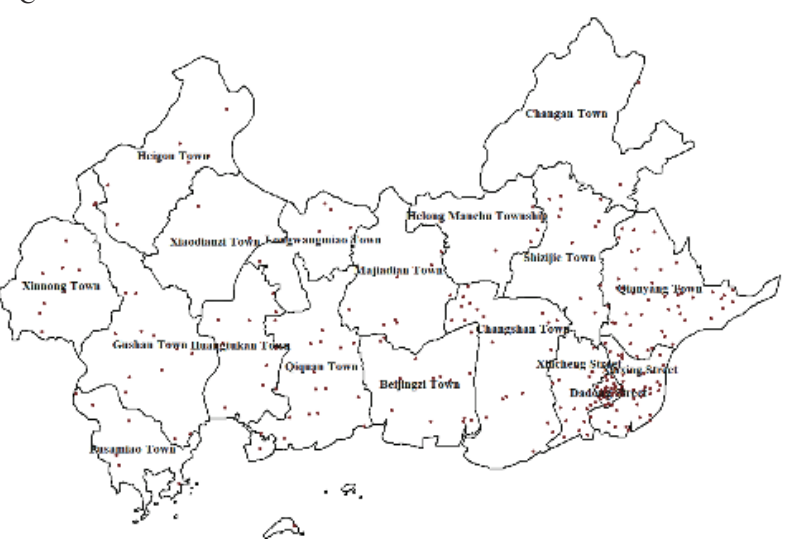

FIGURE 3. Geographic distribution of Hepetitis A (HA) reports in Liaoning Province and two local areas, January 1, 2020 to March 18, 2020. (A) County level distribution of reported HA cases in Liaoning Province. (B) Township-level distribution in Zhuanghe County, Dalian City. (C) Township-level distribution in Donggang County, Dandong City.

types of seafood eaten, food sources, and dining out behavior, were collected by trained, experienced local staff. HA risk factors were identified by univariate and multivariate logistic regression analyses. We found that consumption of raw or undercooked seafood (OR= 11.1, 95\% CI: 6.0-20.6), eating clams (OR=2.5, 95\% CI: 1.6-5.9), eating snapping shrimp (OR=3.1, 95\% CI: $1.6-6.0)$, and eating oysters $(\mathrm{OR}=4.6,95 \% \mathrm{CI}$ : 2.6-8.1) were significantly associated with HAV infection (Table 1).

In March 2020, we collected 30 samples of seafood from local markets, 23 samples of seafood from coastal areas, and 3 samples of water from the Yellow Sea estuary. The samples were sent to the National Marine Environment Monitoring Center to test for the presence of HAV. All samples were negative for HAV.

\section{RESPONSE}

Local governments took several measures in response to the HAV epidemic in Dalian and Dandong including educational, mass-media public communications about the importance of avoiding consuming raw seafood and an encouragement of HA vaccination. By March 14, 4,418 adults in Zhuanghe County of Dalian and 1,861 adults in Donggang County of Dandong were vaccinated. Local governments restricted sale of seafood products in early March to reduce HAV exposure. A total of 22 serum samples from patients with acute HAV infection were obtained and sent to Liaoning Provincial CDC's laboratory for genotyping, and the results are pending. 
TABLE 1. Case-control study on risk factors of Hepetitis A (HA) in Dalian City, Liaoning Province, 2020.

\begin{tabular}{|c|c|c|c|c|c|c|}
\hline \multirow{2}{*}{ Item } & \multicolumn{2}{|c|}{ Cases $(\mathrm{N}=191)$} & \multicolumn{2}{|c|}{ Controls ( $\mathrm{N}=\mathbf{2 7 7})$} & \multirow{2}{*}{$\begin{array}{c}\text { Univariate analysis } \\
\text { OR }(95 \% \mathrm{Cl})\end{array}$} & \multirow{2}{*}{$\begin{array}{c}\text { Multivariate analysis } \\
\text { OR }(95 \% \mathrm{Cl})\end{array}$} \\
\hline & Number & Percentage (\%) & Number & Percentage (\%) & & \\
\hline \multicolumn{7}{|l|}{ Consumption habits } \\
\hline Eating raw seafood & 64 & 33.5 & 41 & 14.8 & $12.0(6.6-21.9)$ & $11.1(6.0-20.6)$ \\
\hline Dining out & 60 & 31.4 & 35 & 12.6 & $3.1(1.9-5.1)$ & $1.4(0.7-2.7)$ \\
\hline \multicolumn{7}{|l|}{ Types of seafood eaten } \\
\hline Big yellow corbicula & 43 & 22.5 & 23 & 8.3 & $3.5(2.0-6.2)$ & $1.1(0.4-2.8)$ \\
\hline Little yellow corbicula & 31 & 16.2 & 20 & 7.2 & $2.4(1.3-4.5)$ & $0.3(0.1-0.8)$ \\
\hline White corbicula & 71 & 37.2 & 62 & 22.4 & $2.0(1.3-3.1)$ & $1.0(0.5-1.8)$ \\
\hline Mixed color corbicula & 22 & 11.5 & 11 & 4.0 & $3.5(1.6-7.9)$ & $2.5(0.8-7.4)$ \\
\hline Sand corbicula & 72 & 37.7 & 64 & 23.1 & $2.1(1.4-3.3)$ & $0.9(0.5-1.7)$ \\
\hline Clams & 41 & 21.5 & 17 & 6.1 & $4.7(2.4-9.0)$ & $2.5(1.6-5.9)$ \\
\hline Snapping shrimp & 84 & 44.0 & 46 & 16.6 & $4.4(2.6-7.2)$ & $3.1(1.6-6.0)$ \\
\hline Cockle & 15 & 7.9 & 9 & 3.2 & $2.5(1.4-6.1)$ & $1.8(0.5-6.2)$ \\
\hline Oysters & 146 & 76.4 & 97 & 35.0 & $6.1(3.8-10.0)$ & $4.6(2.6-8.1)$ \\
\hline
\end{tabular}

\section{DISCUSSION}

HAV is highly infectious and is transmitted through the fecal-oral route (2). HAV that exists in the environment can cause periodic HA epidemics among people if there are sufficient numbers of susceptible individuals. With improvements in health and sanitation and the widespread use of vaccines, the incidence of $\mathrm{HA}$ in Liaoning decreased markedly. Coastal cities like Dalian and Dandong have been highly endemic HA areas in Liaoning with endemic outbreaks characterized by adult cases and peaks in January to March, which is different than areas with endemic HA outbreaks in the summer and autumn (3).

We have shown that despite the increasing number of HA cases in Liaoning, from January 1 to March 18, 2020, the epidemic characteristics remained unchanged. As in the past, cases were mainly from Dalian and Dandong and were sporadic, which was inconsistent with HA outbreak criteria (4). The coastal areas increase in cases were believed to represent the start of a new 3-5-year epidemic cycle. Because this increase occurred during the COVID-19 virus containment activities, local health-care authorities were already prepared for case detection and reporting. After a series of public health measures taken by local governments, the number of reported HA cases declined.

Our study found that consumption of seafood before HA onset was higher than in previous years and that consumption of raw or undercooked seafood were significantly associated with HAV infection. Dalian and Dandong are located on the Liaodong Peninsula where seafood is abundant. From November to April, many types of fresh seafood are sold and consumed by residents, and most people eat raw seafood (5-6). Clams and oysters have been shown to be frequently contaminated with HAV, making HA outbreaks caused by raw seafood consumption common (7-8). A dose-response curve correlating the quantity of clams consumed to the attack rate of HA during the HA outbreak in Shanghai in 1988 (9).

There were two reasons why our study did not find any HAV-positive environmental or seafood samples. First, considering the incubation period of 28 days for $\mathrm{HAV}$, there must be a time lag between exposure to the risk factor and the time of sample collection, which indicated the need for routine monitoring initiated early during infection. Second, the real-time RT-PCR approach has a low sensitivity for finding HAV in such samples (approximately 6\%). However, studies conducted in 2002 found that local offshore seawater and shellfish were significantly contaminated with HAV (10). In June 2019, HAV was detected in 1 shellfish sample during routine monitoring of food safety risks in Liaoning Province. It's worth noting that the results of patients' HAV genotyping testing can only provide evidence of the HAV homology among patients rather than the likely source of infection that the patients are jointly exposed to. Therefore, our findings that reported HA cases increased one month after the initiation of sales of local seafood provides indirect support for our conclusion about the role 
of seafood in the HA increase this year from epidemiological evidence.

We suggest 1) strengthening health education of local residents to avoid consumption of raw or undercooked seafood, 2) encouraging HAV vaccination of adults aged 20 to 54 years to close population immunity gaps and prevent periodic HAV endemic outbreaks, 3) restarting routine immunization and catching up of children who missed vaccinations due to the COVID-19 epidemic, and 4) establishing multisectoral partnerships for HA surveillance in areas with a high prevalence of HAV infections to monitor HAV and its genotypes in patients, the environment, and food with the objective of providing data for updating HA prevention and control strategies.

Acknowledgements: We thank Liaoning provincial, prefectural, and county-level staff who contributed to the field work; we thank all levels of government and the health administrative departments for their strong support; and we thank the hospitals, the marine monitoring departments, and the market supervision departments for their support of the investigation. doi: $10.46234 / \mathrm{ccdcw} 2020.152$

\# Corresponding authors: Hui Zheng, zhenghui@chinacdc.cn; Wenqing Yao, Wenqingyao@sina.com.

\footnotetext{
${ }^{1}$ Liaoning Provincial Center for Disease Control and Prevention, Shenyang, Liaoning, China; ${ }^{2}$ National Immunization Program, Chinese Center for Disease Control and Prevention, Beijing, China; 3 Institute of Preventive Medicine, China Medical University, Shenyang, Liaoning, China; ${ }^{4}$ Dalian City Center for Disease Control and Prevention, Dalian, Liaoning, China; ${ }^{5}$ Dandong City Center for Disease Control and Prevention, Dandong, Liaoning, China; ${ }^{6}$ National Institute for Viral Disease Control and Prevention, Chinese Center for Disease, Control and Prevention, Beijing, China.

${ }^{\&}$ Joint first authors.
}

Submitted: April 14, 2020; Accepted: May 19, 2020

\section{REFERENCES}

1. Chinese Ministry of Health. WS 298-2008 Diagnostic criteria of viral hepatitis A. Beijing: People's Medical Publishing House 2009. http://www.biaozhun8.com/biaozhun-92502/. (In Chinese).

2. World Health Organization. WHO position paper on hepatitis A vaccines - June 2012. Wkly Epidemiol Rec 2012;87(28-29):261-76. https://pubmed.ncbi.nlm.nih.gov/22905367/.

3. Wang Y, Yao WQ, Fang X, Han S. Effect of inclusion of hepatitis A vaccine into expanded program on immunization on incidence of hepatitis A in Liaoning province. Chin J Public Health 2018;34(9): 1285-7. http://www.zgggws.com/article/doi/10.11847/zgggws1 117957. (In Chinese).

4. Sun J, Cui RM, Han Y. Epidemic characteristics of hepatitis A in Liaoning province, 2002-2014. Chin J Public Health 2016;32(3):3635. http://www.zgggws.com/article/id/29712. (In Chinese).

5. Jia XY, Gao XQ, Sun XM, Zhang YQ, Shao Y, Han WQ, et al. Study on relationship between hepatitis A and seamost products. Chin J Dis Control Prev 2003;7(6):576-7. http://d.wanfangdata.com.cn/periodical/ jbkzzz200306039. (In Chinese).

6. Chu FJ, Xu YQ, Min X, Wang XY, Zhang LJ, Cao JY, et al. Characteristics and genotype of hepatitis A virus prevalent strains in Donggang, liaoning province of China, in 2014. Chin J Vacc Immun 2016;20(6):536-7. http://d.wanfangdata.com.cn/periodical/zgjhmy 201406012. (In Chinese).

7. Shi YC, Han Y. The study of 1: 2 case-control of the Hepatitis: a prevalence caused by eating raw shellfish. Theory Pract Chin Med 2000;2000(3):379-80. https://www.docin.com/p-845997880.html\& dpage $=1 \&$ key $\%$ E $8 \% 82 \% 9 \mathrm{D} \% \mathrm{E} 7 \% 82 \% 8 \mathrm{E} \% \mathrm{E} 6 \% 80 \% 8 \mathrm{E} \% \mathrm{E} 4 \% \mathrm{~B} 9 \% 8$ $8 \% \mathrm{E} 6 \% \mathrm{~B} 2 \% \mathrm{BB} \&$ isPay-1\&toflash0\&toImg0. (In Chinese).

8. Yin GC, Mao YD, Cui HS, Chen JX. Study on the relationship between hepatitis A and raw seafood. Chin J Health Stat 1995;12(1): 44-5. https://kns.cnki.net/kcms/detail/detail.aspx?dbcode=CJFD\&file name=ZGWT199501020\&dbnameCJFD9495. (In Chinese).

9. Xu ZY, Li ZH, Wang JX, Xiao ZP, Dong DX. Ecology and prevention of a shellfish-associated hepatitis A epidemic in Shanghai, China. Vaccine, 1992;10(S1):S67-8. https://www.sciencedirect.com/science/ article/pii/0264410X9290547W.

10. Fan JF, Song LC, Zhang XC, Liang YB, Guan DM. Study on the distribution of hepatitis A virus in seawater and shellfish in the coastal area of Liaodong Bay. Mar Sci 2007;31(2):52-4,76. http://d. wanfangdata.com.cn/periodical/hykx200702013. (In Chinese). 